\title{
Article \\ Effect of Storage Time on the Physicochemical Properties of Waste Fish Oils and Used Cooking Vegetable Oils
}

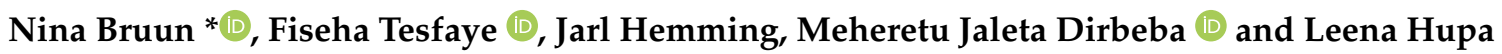 \\ Johan Gadolin Process Chemistry Centre, Åbo Akademi University, Piispankatu 8, FI-20500 Turku, Finland; \\ fiseha.tesfaye@abo.fi (F.T.); jarl.hemming@abo.fi (J.H.); meheretu.dirbeba@abo.fi (M.J.D.); \\ leena.hupa@abo.fi (L.H.) \\ * Correspondence: nina.bruun@abo.fi
}

Citation: Bruun, N.; Tesfaye, F.; Hemming, J.; Dirbeba, M.J.; Hupa, L. Effect of Storage Time on the Physicochemical Properties of Waste Fish Oils and Used Cooking Vegetable Oils. Energies 2021, 14, 101. https://dx.doi.org/10.3390/en14010101

Received: 13 November 2020 Accepted: 24 December 2020 Published: 27 December 2020

Publisher's Note: MDPI stays neutral with regard to jurisdictional claims in published maps and institutional affiliations.

Copyright: () 2020 by the authors. Licensee MDPI, Basel, Switzerland. This article is an open access article distributed under the terms and conditions of the Creative Commons Attribution (CC BY) license (https: / creativecommons.org/ licenses/by/4.0/).

\begin{abstract}
Waste fish oils (FOs) and used cooking vegetable oils (UCOs) are increasingly becoming alternative renewable fuels. However, different physicochemical aspects of these renewable fuels, including the effect of storage, are not well-known. In this work, the effect of the storage period on physicochemical properties of selected samples of FOs and UCOs was investigated. The bio-oils were stored at $4{ }^{\circ} \mathrm{C}$ for up to five years before each experimentation. The chemical properties were characterized using capillary gas chromatography with flame ionization detection (GC-FID) and high-performance size exclusion chromatography including an evaporative light scattering detector (HPSEC-ELSD). Water contents and acid numbers of the bio-oils were determined using the Karl Fischer (KF) titration and the ASTM D 664 methods. Furthermore, the average heating values and surface tension of the bio-oils were determined. According to the results obtained, for all bio-oil types, the concentrations of polymerized triglycerides, diglycerides, and fatty acids and monoglycerides had increased during the storage periods. The physical properties of the bio-oils also showed a small variation as a function of the storage period. The overall results observed indicate that the deterioration of the physicochemical properties of bio-oils can be controlled through storage in dark, dry, and cold conditions.
\end{abstract}

Keywords: free fatty acid; bio-oil; fuel aging; renewable energy sources

\section{Introduction}

Used cooking vegetable oils (UCOs) and waste fish oils (FOs) are of increasing interest as economic feedstock for bio-oils or biodiesel production. Furthermore, compared to petroleum based oils, they are more eco-friendly [1-8]. However, they have limited oxidative stability as their source is, i.e., fresh vegetable oils [3]. Their contribution to a carbon-neutral energy system is illustrated in Figure 1.

Bio-oils usage in the transport sector is increasing. The usage of waste-derived oils, not in the food production chain, offers a feasible way to increase the share of carbonneutral fuel alternatives. In the marine sector, sulfur-oxide $\left(\mathrm{SO}_{\mathrm{x}}\right)$ emissions from engines cause fine dust generations that can lead to serious health issues [9]. The EU is actively promoting and passing legislations for a global maritime emissions cut. Recently, the United Nations specialized agency, the IMO-International Maritime Organization, agreed to reduce shipping greenhouse gas emissions by $\geq 50 \%$ until 2050 [10]. According to the revised Sulfur Directive, since the beginning of 2020, maximum sulfur content of marine fuels is reduced to $0.5 \%$, i.e., down from the 2012 Sulfur Directive limit $3.5 \%$, globally [9]. Bio-oils such as UCOs and FOs with a low sulfur content are excellent alternative marine fuels. Thus, the ongoing intensive research related to the bio-oils quality and usage can contribute to the transition towards increasing usage of the eco-friendly fuels.

Vegetable oils, consisting of triglycerides, are used worldwide in restaurants and households for frying food. During frying, the temperature of the oils can reach as high as $190{ }^{\circ} \mathrm{C}[11]$, which creates favorable conditions for several reactions to take place within 
the oil and its surroundings. The oils' original properties are significantly affected during the frying step as the triglycerides degrade thermally and chemically [11]. In general, three major types of reactions may take place during frying: oxidation, hydrolysis, and thermal degradation of triglycerides [12]. These reactions may result in the formation of free fatty acids (FFAs), glycerol, monoglycerides, and diglycerides. An increase in saturated and monounsaturated fatty acids can also occur [1,11,13-16].

During the frying process, the cooking oils are exposed to moisture, air, and an elevated temperature $\left(140<\mathrm{T}\left({ }^{\circ} \mathrm{C}\right)<180\right)$, which cause hydrolytic and oxidation reactions of the oils. The hydrolytic reactions result in diglycerides, FFAs, monoglycerides, and glycerol. The oxidation reactions, which are the main reactions in the presence of air, result in oxidized polymers, dimers, and monomers [2,17-19].

In most cases, tocopherols, dimers of fatty acids, or sterols formed by peroxidation are bridged by oxygen. The oxidation and polymerization reactions that increase the viscosity of UCOs depend on the duration of frying [11,20]. In addition, many toxic substances are formed in the vegetable oils during frying. For this reason, in 2002, the European Commission has forbidden the addition of used cooking oils in animal feed [1]. The concentration of UCOs is increasing worldwide because of a surge in edible oil consumption [1]. UCOs are much cheaper than fresh vegetable oils. They can be directly used as marine engine fuel, for example, or by using a transesterification reaction, in biodiesel production [18] as depicted in Figure 1.

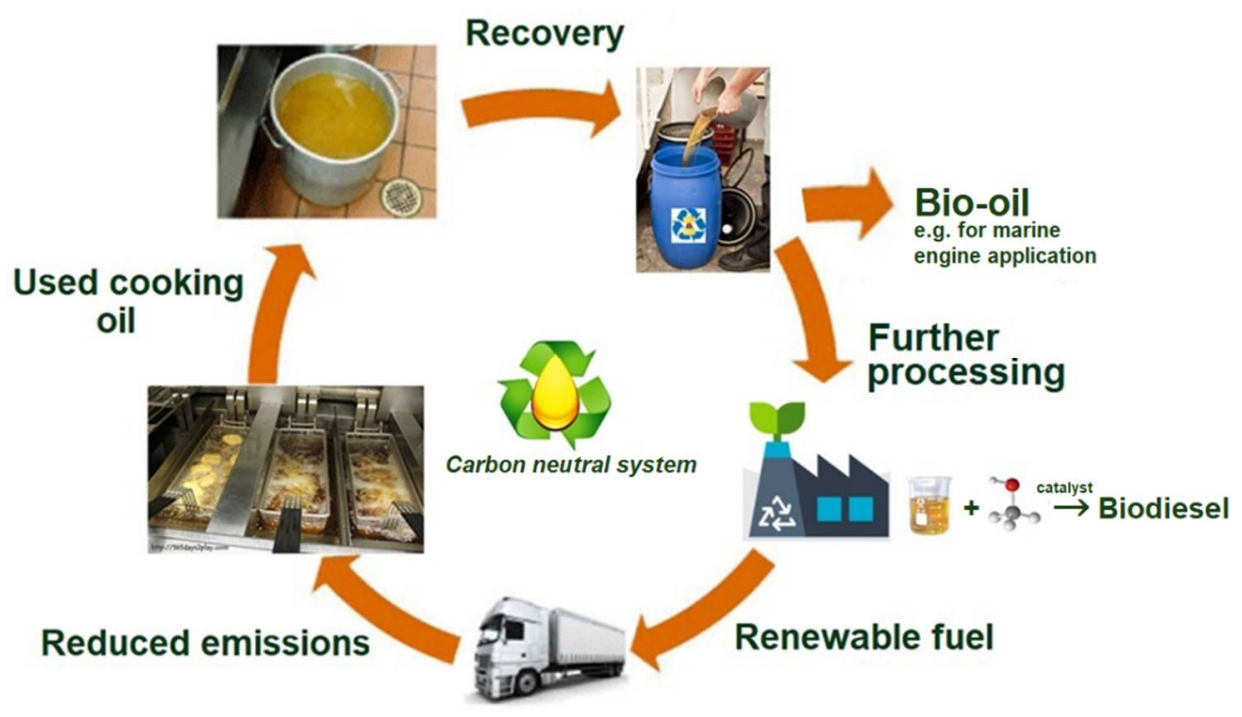

Figure 1. Schematic diagram showing the role of used cooking vegetable oils (UCOs) enabling a carbon neutral energy system.

The storage conditions of bio-oils contribute to the change in quality over time. Research on this topic is relatively fresh; the majority of the previous publications by different authors regarding the effect of storage on bio-oils quality have taken place between the years 2007 and 2019.

Various chemical reactions can occur during the storage of bio-oils and biodiesels constituting FFAs and water [1,21,22]. For UCOs, the FFA value, water content, viscosity, and density are variables that increase compared to fresh vegetable oil $[1,23]$. Light, heat, and dissolved metal ions are conducive to vegetable oils oxidation and increased acidity. Oxidation begins at the carbon double bond and the reaction mechanism is described as a chain reaction of free radicals [24,25].

Over an extended period, inappropriate storage conditions cause oxidation of oils, which lead to higher viscosity and necessity for filtration prior to use in an engine [26]. When storing bio-oils, the following conditions should be met: impurities removed, cool and constant temperature conditions, and protected from exposure to light (including 
sunlight) [26]. To determine the oxidation rate of bio-oils at elevated temperatures, some researchers $[3,24,27]$ conducted experiments in an oven ranging from 80 to $110^{\circ} \mathrm{C}$.

Ushakov et al. [28] demonstrated that crude fish-oils show a higher acidity and viscosity, as well as lower lubricity than conventional diesel fuels. The fish-oils' poor fuel properties could be due to impurities like FFAs (a primary oxidation product), pigments, minerals, moisture, and phospholipids in unrefined fish-oil [29]. Higher FFA and phospholipid levels reduce the fuel quality of fish-oils, requiring additional refining processes, such as degumming and neutralization. Phospholipids in fish-oils polymerize due to heat and build up deposits on the combustion chamber walls and the surfaces of cylinders in engines. The deposits can also clog injectors and valves [26,30]. The hydrolysis of triglycerides in the presence of water may lead to high FFA due to bad feedstock storage conditions. The high FFA cause low stability of oil during storage and corrosion during usage [30,31]. Generally, the water content of bio-oil hinders ignition, decelerates flame propagation, and decreases the heating value [30,32].

Surface tension profoundly influences the product quality of fuels, detergents, inkjet products, lubricants, and pharmaceuticals. In addition, in wetting, penetration, foaming and formation of droplets, surface tension of a liquid have a determinant role [33,34], thus governing a liquid's physicochemical behavior. Surface tension varies with pressure, temperature, and for mixtures, also on the mixture composition. If the fuel is used in internal engines, the injection system's droplet formation and the atomization properties related to the ignition quality are greatly influenced by surface tension [35,36]. Increasing surface tension results in increased spray atomization, which suggests a better mixing of fuel with air [37]. Recently, Morón-Villarreyes et al. [35] measured the surface tension of biodiesels, taking water as a reference liquid utilizing the drop weight technique by applying Tate's Law. Tyowua et al. [38] measured vegetable oils' surface tension by the du Noüy tensiometer method at room temperature. It is a well-known fact that the fuel atomization process that affects the combustion process depend on surface tension. However, there are only limited number of published information regarding the surface tension of UCOs and FOs to be used as unmodified fuels in diesel engines.

In our previous works, the chemical, physical, and thermal properties and corrosivity of fresh UCOs and FOs were analyzed [27,39]. In this work, the storage time effect on the bio-oils' physicochemical and thermal properties was investigated. Samples of the bio-oils were placed in a refrigerator at $4{ }^{\circ} \mathrm{C}$ for up to five years before each measurement. In general, the results obtained contribute to the understanding of the impact of storage time on the quality of bio-oils.

\section{Materials and Methods}

\subsection{Materials}

The properties and composition of two waste fish oils (FO1-15 and FO1-18) and six used cooking oils (UCO1-15, UCO2-15, UCO3-15, UCO1-18, UCO2-18, and UCO3-18) were measured. The samples were kindly provided by VG EcoFuel Oy (Uusikaupunki, Finland). The numbers after each sample name FO and UCO refer to the batch and the year of delivery, i.e., for example FO1-15 means 1st fish oil sample received in 2015 and UCO1-18 means 1st used cooking oil sample received in 2018. The FOs were produced from the gutting remains of rainbow trout after extracting the edible oil, while the filtered UCOs originated from frying vegetable oils used in restaurants. As a reference for all bio-oils, a commercial product (COref) was used. The composition of COref is mostly aliphatic hydrocarbons, in which the dominant compounds are linear saturated hydrocarbons with composition up to $\mathrm{C} 30$, the largest single compounds being in the range $\mathrm{C} 14-\mathrm{C} 26$. The bio-oils were stored over the whole time (from 2 to 5 years) in a refrigerator in white opaque plastic bottles with screw plastic lids at $4{ }^{\circ} \mathrm{C}$ before the analyses. 


\subsection{Methods}

\subsubsection{Chemical Properties}

- Water content and acid number

KF (Karl Fischer) titration with an automatic coulometric titrator (Metrohm 851 Titrando instrument) connected to the oven (860 KF Thermoprep) at $110{ }^{\circ} \mathrm{C}$ was used to measure the oils' water content. The bio-oil's acid number (AN) was measured by the ASTM D 664 method using the Solvotrode glass electrode in a Metrohm 888 Titrando. More details of the experimental procedure and equipment used for the water content and AN measurements are given in [39].

- Oil composition

Capillary gas chromatography with flame ionization detection (GC-FID) (Perkin Elmer Autosystem XL) was used to quantify the amount of FFAs and monoglycerides in silylated oil samples. The experimental error for this method is estimated to be $\pm 5 \%$. An Agilent J\&W HP-1, $25 \mathrm{~m}$ (L) $\times 0.200 \mathrm{~mm}$ (ID) column with film thickness $1.1 \times 10^{-7} \mathrm{~m}$ was used. As a carrier hydrogen gas was used with a flow rate of $0.8 \mathrm{~mL} / \mathrm{min}$. Details on the oven temperatures and gas flow rates can be found in [39]. By GC-MS analysis with an HP 6890-5973 GC-MSD instrument, the individual components were identified, using as carrier helium gas.

By applying a wide-bore short column GC-FID (PerkinElmer Clarus 500) di- and triglycerides were analyzed. Parameters of the column (Agilent HP-1/SIMDIST) were $0.15 \mu \mathrm{m}$ (film thickness) and $\sim 6 \mathrm{~m}$ (L) $\times 0.530 \mathrm{~mm}$ (ID). Hydrogen was the carrier gas with a flow rate of $7 \mathrm{~mL} / \mathrm{min}$. Details of the temperatures in a wide-bore GC-oven and gas flow rates can be found in [39].

- Elemental analyses

High-performance size-exclusion chromatography connected to an evaporative light scattering detector (HPSEC-ELSD, Shimadzu Corporation, Kyoto, Japan, Shimadzu 10A series modular HPLC; and SEDERE SA, ELSD detector, Sedex 85 LT-ELSD), using tetrahydrofuran as eluent, was used to detect polymerized triglycerides, triglycerides, diglycerides, and fatty acids and monoglyceride.

The $\mathrm{C}$ and $\mathrm{H}$ contents of the FOs, UCOs, and COref were analyzed using a FLASH 2000 organic elemental analyzer from Thermo Scientific (Cambridge, UK). The elemental analysis was performed in the year 2020 for all the oil samples collected during the years 2015 and 2018. Elemental analysis with the organic elemental analyzer was carried out as follows: First, the analyzer was calibrated with organic analytical standards, i.e., methionine, cysteine, sulfanilamide, and BBOT (2,5-Bis(5-tert-butyl-2-benzooxazol-2-yl) thiophene), all from Thermo Scientific (Cambridge, UK). Then, about $2 \mathrm{mg}$ samples of the oils were weighed into tin capsules, which were partly filled with an adsorbent-Chromosorb W/AW from ThermoQuest Italia S.p.A. (Milan, Italy). The adsorbent was used to minimize the loss of volatile organic compounds from the oils during analysis with the analyzer. Next, the tin capsules with the oil samples contained in them were combusted in the combustion chamber of the analyzer. The $\mathrm{CO}_{2}$ and $\mathrm{H}_{2} \mathrm{O}$ gas mixture from the combustion chamber was then separated in the chromatographic column of the analyzer, and the gases were detected by the thermal conductivity detector (TCD) of the analyzer. Finally, the electrical signals from the TCD were processed using Eager Xperience software, version 1.2. For each oil, the experiments were repeated three times, and the average values on a $w t \%$ oil basis were reported. Further details of the experimental procedures for the elemental analysis with the organic elemental analyzer are available in [40].

\subsubsection{Density, Kinematic Viscosity, and Surface Tension Measurements}

By applying a pycnometer, the density of all samples was measured at $21^{\circ} \mathrm{C}$. A Cannon Fenske (reverse flow) viscometer, capillary 511 20, using the ASTM D 2515 method, 
in a thermostatic bath at $40 \pm 0.5^{\circ} \mathrm{C}$, were applied to measure kinematic viscosity. Each sample was measured in three replications.

The surface tension of the bio-oils was measured using the du Noüy KSV Sigma 70 tensiometer. The electrobalance and the moving mechanism were collected on a PC. For reproducibility checks, the measurements of each sample were conducted three times. Before the measurements, the platinum du Noüy ring was heated to glowing in a blue Bunsen flame and between each measurement purified with ethanol and acetone and dried in contamination-free air. The sample container was purified with ethanol and acetone and dried. The container was filled with $40 \mathrm{~mL}$ of bio-oil sample before each surface tension measurement. The temperature during the measurements was $24^{\circ} \mathrm{C}$.

\subsubsection{Thermal Properties}

The higher heating values (HVs) of the bio-oils were determined by burning them in an adiabatic oxygen bomb calorimeter (model Parr 1341), according to SFS-EN 14918:2009. Bio-oil samples weighing between 400 and $800 \mathrm{mg}$ were put in the bomb calorimeter and charged with oxygen at a pressure of $\sim 30 \mathrm{~atm}$. The experiments were run twice for each sample.

\section{Results and Discussion}

\subsection{Oil Composition}

3.1.1. Polymerized Triglycerides, Diglycerides, and Fatty Acids and Monoglycerides

During the two and five years of storage, the polymerized triglycerides, diglycerides, and fatty acids and monoglycerides of all FOs and UCOs had increased (Table 1). Apparent differences were measured for the polymerized triglycerides in FO compared to those in UCOs during the five-year storage period.

Table 1. Summary of the contents of polymerized triglycerides, diglycerides, and fatty acids and monoglycerides in the bio-oils after different storage times using high-performance size exclusion chromatography (HPSEC). n.d. stands for not detected (detection limit $<0.3 \%$ ).

\begin{tabular}{|c|c|c|c|c|c|c|}
\hline \multirow[t]{3}{*}{ Sample } & \multicolumn{2}{|c|}{ Polymerized Triglycerides (\%) } & \multicolumn{2}{|c|}{ Diglycerides (\%) } & \multicolumn{2}{|c|}{ Fatty Acids and Monoglycerides (\%) } \\
\hline & \multicolumn{2}{|c|}{ Year of Analysis } & \multicolumn{2}{|c|}{ Year of Analysis } & \multicolumn{2}{|c|}{ Year of Analysis } \\
\hline & 2015 & 2020 & 2015 & 2020 & 2015 & 2020 \\
\hline FO1-15 & n.d. & 4.3 & 0.3 & 1.7 & 0.7 & n.d. \\
\hline UCO1-15 & 5.6 & 6 & 12.6 & 14.6 & 4.2 & 6.1 \\
\hline UCO2-15 & 5.6 & 6 & 13.8 & 15.3 & 4.6 & 6.6 \\
\hline \multirow[t]{2}{*}{ UCO3-15 } & 4.8 & 6.6 & 6.2 & 8.2 & 1.7 & 3.1 \\
\hline & 2018 & 2020 & 2018 & 2020 & 2018 & 2020 \\
\hline FO1-18 & n.d. & 1.7 & 7.6 & 11.8 & 10.8 & 14.0 \\
\hline UCO1-18 & 1.2 & 5.7 & 4.5 & 10.1 & 1.1 & 4.7 \\
\hline UCO2-18 & 1.3 & 5.1 & 5.10 & 10.3 & 1.6 & 4.9 \\
\hline UCO3-18 & 1.3 & 6 & 5.2 & 10.8 & 1.6 & 5.8 \\
\hline
\end{tabular}

No marked differences in the patterns of changes in the polymerized triglycerides or fatty acids and monoglycerides of the UCOs were analyzed after the storage periods (Table 1). In contrast, the changes in the contents of polymerized triglycerides or fatty acids and monoglycerides were not consistent. When comparing the two series, the original batch's oil component share is likely to vary depending on the batch preparation day, thus most likely depending on the raw material variations for the oil.

The increased concentrations of polymerized triglycerides, diglycerides, and fatty acids and monoglycerides could be due to the effect of the storage period on hydrolysis and oxidation reactions in the bio-oils $[1,11,13,16,22]$. 


\subsubsection{Total Free Fatty Acid}

Total FFAs of the bio-oils were analyzed by the GC method with an estimated accuracy of $\pm 5 \%$. For FO1-15, the change in total FFA between those measured in 2015 and 2020 are insignificant. For the used cooking vegetable oil samples, the overall change in the total FFAs were noticeably outside the experimental error margins and are presented in Figure 2. As can be seen in Figure 2, the total FFAs of the UCOs had decreased in the batches stored for a five-year period. However, the trends after two years for the batches from $2018 \mathrm{did}$ not show consistent results.

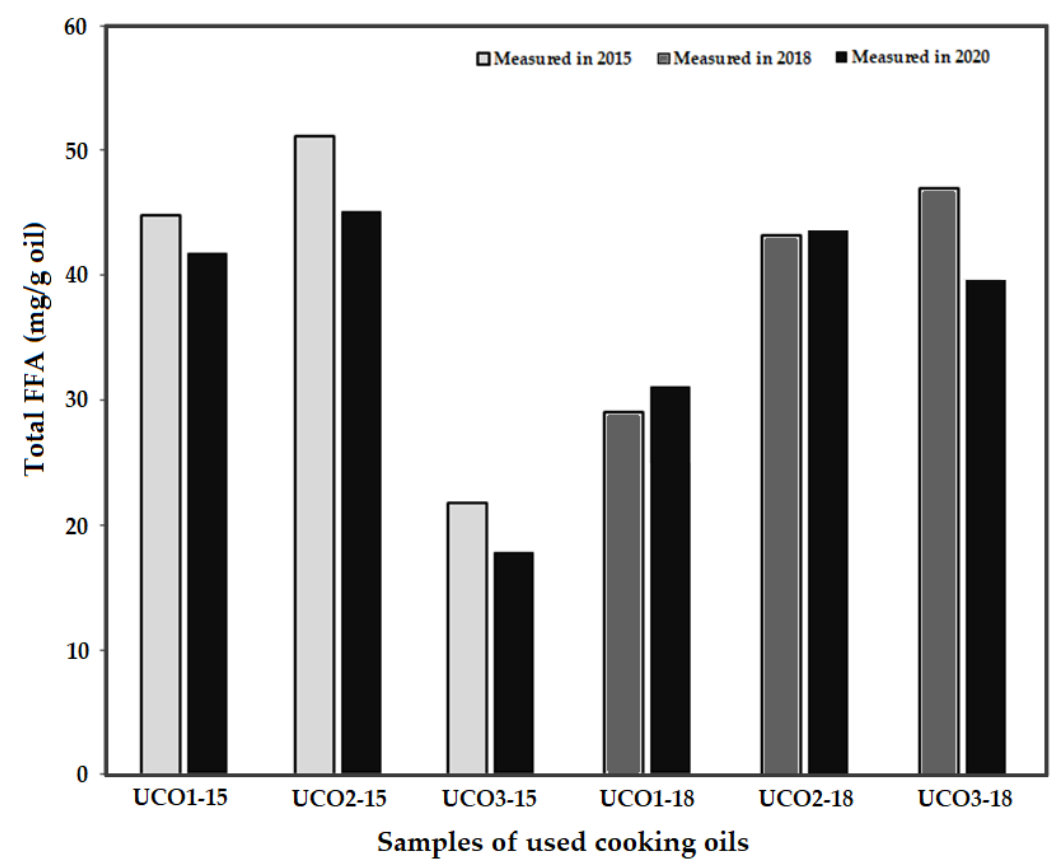

Figure 2. Change in total free fatty acids (FFAs) of different UCOs measured as received and after two and five years' storage.

According to Santos et al. [11], the oxidation and polymerization reactions within the UCOs also depend on the duration of frying prior to the recovery of the UCOs. Differences in the total FFAs for different bio-oil samples before and after the storage were assumed to depend partly on variations in the frying periods. A summary of the total FFAs together with the saturated, unsaturated and monoglycerides obtained by the GC analyses are provided in Table S1.

\subsubsection{Acid Number}

The ANs for the FOs and UCOs are presented in Figure 3. The AN of the bio-oils was analyzed with the ASTM D 664 method. The highest increase in AN was observed during a two-year storage period for FO1-18, i.e., $2.5 \mathrm{mg} \mathrm{KOH} / \mathrm{g}$. The waste fish oil already had a high level of AN (about $25 \mathrm{mg} \mathrm{KOH} / \mathrm{g}$ oil) when delivered. It did not meet the requirements for the bio-fuels for marine engine applications, with the maximum limit of $15 \mathrm{mg} \mathrm{KOH} / \mathrm{g}$ oil. AN for the higher quality FO1-15, with the low initial value $(1.7 \mathrm{mg} \mathrm{KOH} / \mathrm{g}$ oil), increased only by $0.8 \mathrm{mg} \mathrm{KOH} / \mathrm{g}$ oil during the five-year storage period.

For the used cooking vegetable oil UCO1-15, the acid number increased from $8.9 \mathrm{mg} \mathrm{KOH} / \mathrm{g}$ oil to $11.1 \mathrm{mg} \mathrm{KOH} / \mathrm{g}$ oil during the five-year storage. For UCO1-18, UCO2-18, and UCO3-18, the AN has increased between 0.5 and $1.3 \mathrm{mg} \mathrm{KOH} / \mathrm{g}$ oil in two years.

The AN of all bio-oils increased consistently during the two and five year periods of storage. The assumption is, that the increase in acidity depends on the hydrolysis and oxidation reactions $[24,41]$. 


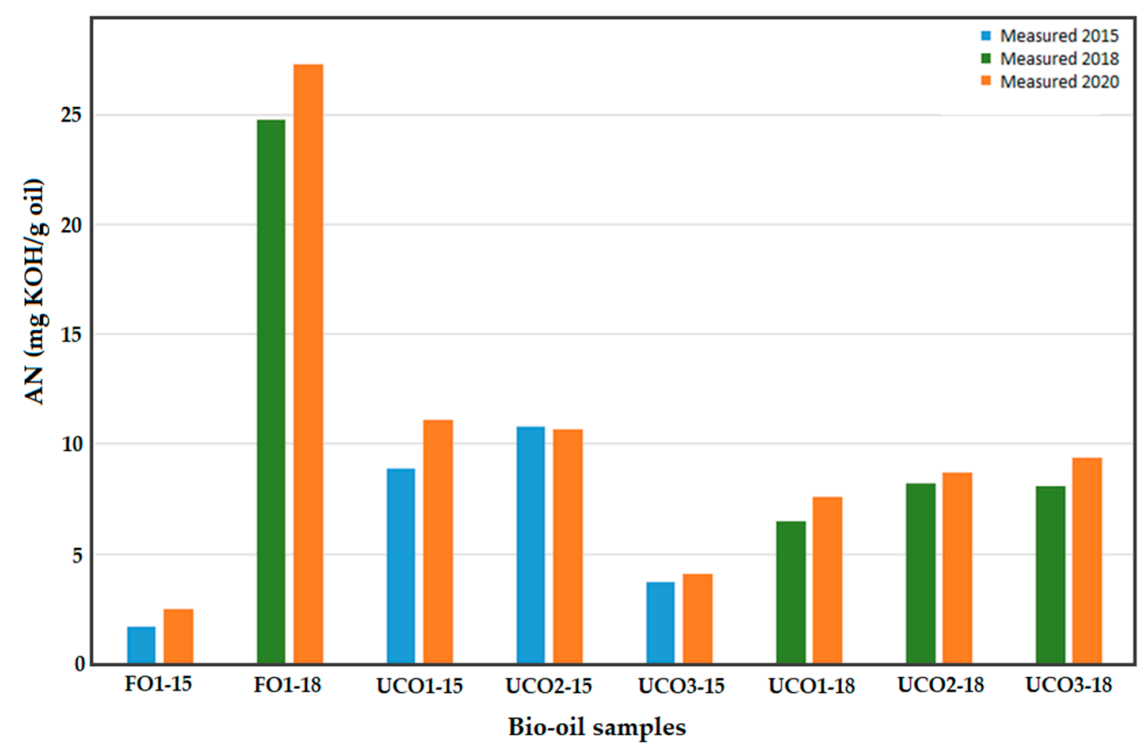

Figure 3. Acid number for bio-oils measured in the years 2015, 2018, and 2020.

The theoretical acid numbers (mg KOH/g oil) were calculated according to Equation (1) using the GC analysis determined total FFAs of the samples. The measured and calculated acid number values as functions of the total measured FFA content are shown in Figure 4. The differences between the measured and calculated values are assumed to depend partly on volatile fatty acids, such as formic acid, acetic acids, or some inorganic acids that are not detected in the GC analysis. Some oil samples, for example, FO1-18 may also include a preservative (formic acid) added against ageing [27]. The total FFA concentrations analyzed using GC (given in Table S1) were converted to theoretical ANs, mg KOH/g oil. All the GC analyses of the oil samples received in 2015 and 2018 were made in 2020.

$$
\mathrm{AN}\left(\frac{\mathrm{mg} \mathrm{KOH}}{\mathrm{g}} \text { oil }\right)=[\text { Total FFA }]\left(\frac{\mathrm{mmol}}{\mathrm{g}}\right) \cdot 56.1 \mathrm{mg} \mathrm{KOH} / \mathrm{mmol}
$$

\subsubsection{Water Content}

The water content for the bio-oil samples was measured with the KF titration method. Generally, the water content of all bio-oils had increased during the storage (Table 2), as also reported by Meng et al. [42]. As shown in Table 2, the water content of FO1-15 had increased by $430 \mathrm{ppm}$ after five years of storage time. The water content in the five-year old UCO samples, UCO1-15, UCO2-15, and UCO3-15, had increased by about 240-560 ppm. The increase in water content of UCO1-18, $111 \mathrm{ppm}$ in two years, was in line with the five-year samples. According to specifications for marine engines, the water content of biofuels must be below $0.2 \% v / v$ [43]. Thus, all the samples except for FO1-18 had a water content below this limit, both before and after the storage.

Table 2. Water content of bio-oils measured in the years 2015, 2018, and 2020.

\begin{tabular}{cccccc}
\hline \multicolumn{7}{c}{ Water Content (ppm) } & \multicolumn{2}{c}{ Year } \\
\hline Sample & $\mathbf{2 0 1 5}$ & $\mathbf{2 0 2 0}$ & Sample & $\mathbf{2 0 1 8}$ & $\mathbf{2 0 2 0}$ \\
\hline FO1-15 & 473 & 900 & FO1-18 & 2473 & 2720 \\
UCO1-15 & 538 & 1094 & UCO1-18 & 1662 & 1773 \\
UCO2-15 & 706 & 1015 & UCO2-18 & 1449 & 1734 \\
UCO3-15 & 740 & 977 & UCO3-18 & 1403 & 1686 \\
\hline
\end{tabular}




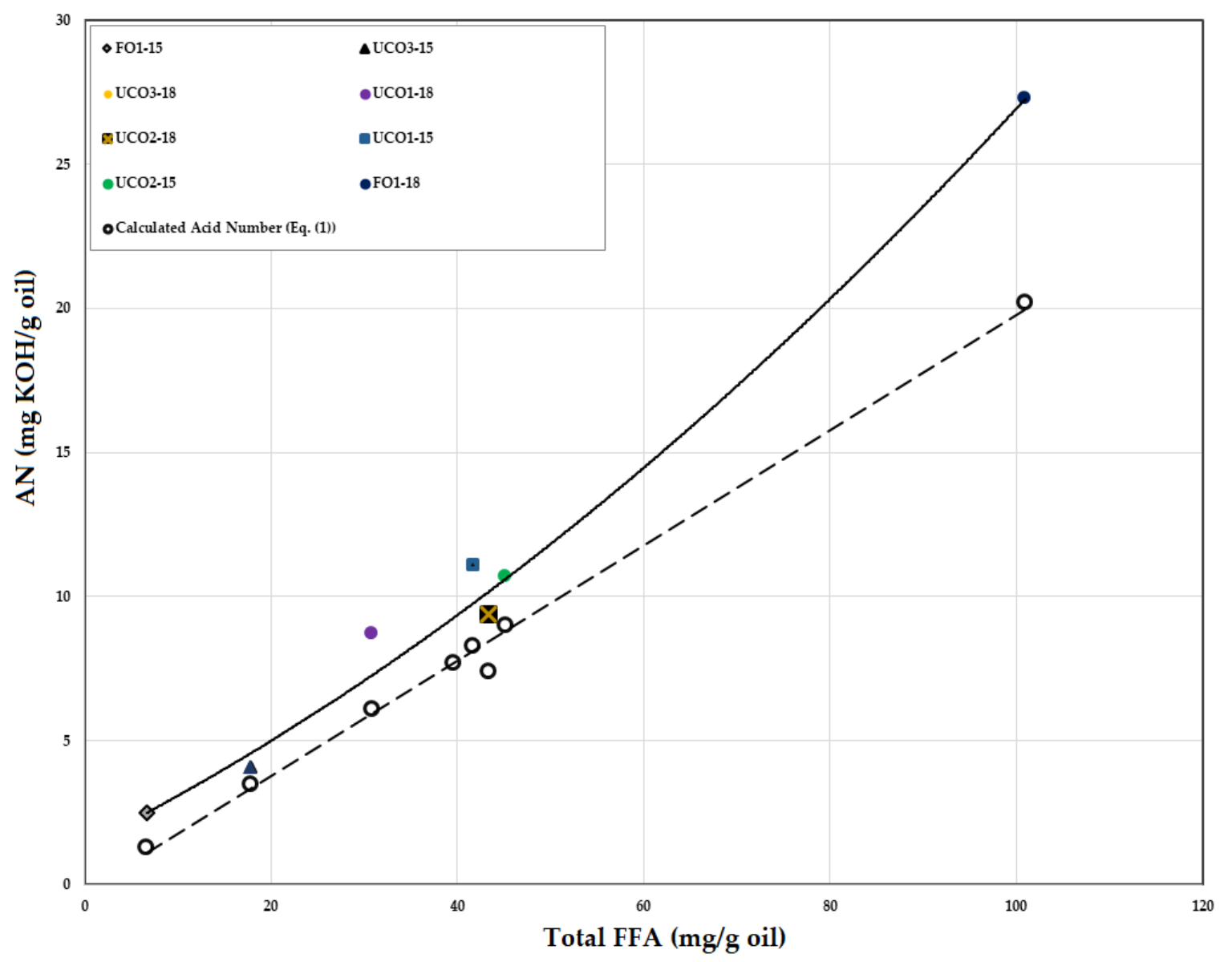

Figure 4. Measured and theoretically calculated acid number (AN) values as functions of the measured total FFA after two and five years' storage. The solid and dashed lines give the least-square fitting of the experimental and calculated values, respectively.

According to Karmakar et al. [44], water molecules are attracted to free fatty acids because of their hygroscopic properties. Mono- and diglycerides also effectively bind water into vegetable oil fuels [45]. This increase of water content with aging could be higher if stored at room temperature and in a relatively open system of storage.

\subsubsection{Elemental Composition: $\mathrm{H}$ and $\mathrm{C}$ Contents of the Oils}

Table 3 lists the carbon and hydrogen contents and their ratio on a $\mathrm{wt}_{\mathrm{t}} \%$ for the FOs, UCOs, and COref measured with the CHNS-O (carbon, hydrogen, nitrogen, sulfur, and oxygen) elemental analyzer. The $\mathrm{C} / \mathrm{H}$-ratio of most oils was in the range of 6.4 to 6.6, independently of the storage time.

The $\mathrm{C} / \mathrm{H}$-ratios are typical for triglycerides, such as triolein, trilinolein, tripalmitolein, and tristearin, found in waste fish oils [46,47] and used cooking oils [48].

For COref, consisting of hydrocarbons [27], the carbon and hydrogen concentrations were higher than those in the bio-oils. Our bio-oil studies show that over a maximum of five years there was not much oxidation in our samples, because all the measured $\mathrm{H}$ and $\mathrm{C}$ contents were on the same level for the bio-oils.

In this work, the values were roughly the same before and after the storage, thus verifying that the amount of volatile species due to oxidation reactions was small in cold storage conditions. 
Table 3. $\mathrm{H}$ and $\mathrm{C}$ contents and mass ratios of the bio-oils and a commercial product analyzed with CHNS-O elemental analyzer. The overall average standard deviation is 0.4 .

\begin{tabular}{|c|c|c|c|}
\hline Sample & $\mathrm{C}(\mathrm{wt} \%)$ & $H(w t \%)$ & C to H Ratio (Mass Basis) \\
\hline FO1-15 & 79.1 & 12.1 & 6.5 \\
\hline FO1-18 & 76.6 & 11.8 & 6.5 \\
\hline UCO1-15 & 76.8 & 12.0 & 6.4 \\
\hline UCO2-15 & 76.2 & 11.9 & 6.4 \\
\hline UCO3-15 & 76.3 & 11.9 & 6.4 \\
\hline UCO1-18 & 76.4 & 11.9 & 6.4 \\
\hline UCO2-18 & 76.8 & 11.0 & 7.0 \\
\hline UCO3-18 & 76.7 & 12.0 & 6.4 \\
\hline COref & 86.2 & 13.1 & 6.6 \\
\hline
\end{tabular}

\subsection{Thermal Properties}

$\mathrm{HV}$ of the Bio-Oils

All the measured HVs of the oils before and after storage are collected to Table 4 . The average heating value of the bio-oils was $39.8 \pm 0.3 \mathrm{MJ} / \mathrm{kg}$ oil, comparable to the typical value $\sim 40 \mathrm{MJ} / \mathrm{kg}$ [49] for heavy fuel oils and biodiesel prepared from waste cooking oils $39.4 \mathrm{MJ} / \mathrm{kg}$ [50]. The heating value for the reference oil (COref) is significantly higher, $45.7 \mathrm{MJ} / \mathrm{kg}$ oil. According to Capuano et al. [2], used cooking vegetable oils have mean heating values in the range $32.2-41.8 \mathrm{MJ} / \mathrm{kg}$ and the average value determined for the bio-oils in this work falls in this range. The HVs of vegetable oils are lower than those of diesel due to high oxygen content [51]. According to Jiménez Espadafor et al. [52] and Hoekman et al. [50], the oxygen atoms in the triglyceride molecules, about $11 \%$, are responsible for a $4 \%$ decrease in the heating value. The oxygen atoms in the fatty acids in the bio-oils could explain the circa $12 \%$ difference in the HVs compared to aliphatic hydrocarbons COref [27].

The chemical and physical changes during the storage time (maximum five years) had not significantly affected the heating values of the original bio-oils. The studies of Wahyudi et al. [51] on vegetable oils suggest that the oxidation reaction has a noticeable impact on the HVs of the oils. CHNS-O elemental analyses (Table 3) of the bio-oils in this work show that the composition of the bio-oils was not affected over the five years of storage. This is consistent with the negligible changes in the HVs measured after the long storage times.

According to Liu et al. [53], the HV of biodiesel produced from Jatropha curcas showed a marked decrease in an accelerated oxidation test upon the oil-blend oxidation. The atmosphere in our storage conditions was likely to prevent oxidation, thus explaining the almost insignificant changes in the HV over different storage periods.

Table 4. The heating value of the fish oils (FOs) and UCOs samples determined before and after storage periods of two and five years.

\begin{tabular}{ccccccc}
\hline \multirow{2}{*}{ Sample } & \multicolumn{2}{c}{ Heating Value (MJ/kg Oil) } & & & \multicolumn{2}{c}{ Heating Value (MJ/kg Oil) } \\
\cline { 2 - 3 } & $\mathbf{2 0 1 5}$ & $\mathbf{2 0 2 0}$ & & & $\mathbf{2 0 1 8}$ & $\mathbf{2 0 2 0}$ \\
\hline FO1-15 & 39.8 & 40.1 & & FO1-18 & 40.3 & 39.7 \\
UCO1-15 & 40 & 39.5 & & UCO1-18 & 39.6 & 40.0 \\
UCO2-15 & 40 & 39.6 & & UCO2-18 & 39.7 & 40.0 \\
UCO3-15 & 39.9 & 39.8 & & UCO3-18 & 39.7 & 39.7 \\
\hline
\end{tabular}

\subsection{Physical Properties}

Goodrum and Eitcman [37] indicated that dynamic viscosity, density, surface tension, vapor pressure, and specific heat are the most relevant physical properties of oils. 


\subsubsection{Density of the Bio-Oils}

During the storage periods of the bio-oils, density increased or remained at the same level (Table 5). A relatively small increase was measured for the fish oil FO1-18, which is an increase of $3 \mathrm{~kg} / \mathrm{m}^{3}$ in two years. The only exception was UCO2-18, for which the density decreased slightly from $917 \mathrm{~kg} / \mathrm{m}^{3}$ to $914 \mathrm{~kg} / \mathrm{m}^{3}$ in five years. The water content for the same soil increased by $285 \mathrm{ppm}$ (from $1449 \mathrm{ppm}$ to $1734 \mathrm{ppm}$, Table 2), which probably can also have affected the density change.

Table 5. Physical properties of bio-oils before and after two and five years of storage.

\begin{tabular}{|c|c|c|c|c|c|c|}
\hline \multirow[t]{2}{*}{ Sample } & \multicolumn{2}{|c|}{$\begin{array}{c}\text { Kinematic Viscosity }\left(\mathrm{mm}^{2} / \mathrm{s}\right) 40 \circ \mathrm{C} \\
\text { Year of Analysis }\end{array}$} & \multicolumn{2}{|c|}{$\begin{array}{l}\text { Density }\left(\mathrm{kg} / \mathrm{m}^{3}\right) 21^{\circ} \mathrm{C} \\
\text { Year of Analysis }\end{array}$} & \multicolumn{2}{|c|}{$\begin{array}{c}\text { Surface Tension }(\mathrm{mN} / \mathrm{m}) \\
\text { Year of Analysis }\end{array}$} \\
\hline & 2015 & 2020 & 2015 & 2020 & & 2020 \\
\hline FO1-15 & 31.9 & 36.4 & 916 & 917 & - & 33.25 \\
\hline UCO1-15 & 40.6 & 43.6 & 914 & 915 & - & 32.91 \\
\hline UCO2-15 & 41.3 & 43.6 & 916 & 916 & - & 32.99 \\
\hline \multirow[t]{2}{*}{ UCO3-15 } & 44.3 & 44.1 & 915 & 916 & - & 33.03 \\
\hline & 2018 & 2020 & 2018 & 2020 & & 2020 \\
\hline FO1-18 & 26.6 & 35.7 & 916 & 919 & - & 32.97 \\
\hline UCO1-18 & 40.7 & 41.0 & 916 & 916 & - & 33.01 \\
\hline UCO2-18 & 40.7 & 40.0 & 917 & 914 & - & 33.14 \\
\hline UCO3-18 & 40.3 & 41.7 & 916 & 918 & - & 33.12 \\
\hline
\end{tabular}

\subsubsection{Kinematic Viscosity of the Oils}

Kinematic viscosities measured for each bio-oil sample at $40{ }^{\circ} \mathrm{C}$ showed a tendency of increasing with the storage time (Table 5). The only exceptions are the kinematic viscosities of UCO3-15, UCO1-18, and UCO2-18, which remain within the experimental error range of $\pm 0.7 \mathrm{~mm}^{2} / \mathrm{s}$. For FO1-18, the increase in kinematic viscosities was the highest, $9.1 \mathrm{~mm}^{2} / \mathrm{s}$ in two years. The kinematic viscosities of FO1-15, UCO1-15, UCO2-15, and UCO3-18 increased by an average of $2.8 \mathrm{~mm}^{2} / \mathrm{s}$ during the storage periods. For the UCO samples, the concentration of polymerized triglycerides had increased during the storage periods (Table 1), thus contributing to the observed viscosity increases.

After examining several different vegetable oils, Sahasrabudhe et al. [54] concluded that the viscosity and density varied depending on the oil type. In contrast, the variations in the types of the oils did not affect the bio-oils' surface tension. The temperature (between 22 and $200{ }^{\circ} \mathrm{C}$ ) had a significant effect on all three physical properties. At the saturation level, the number of carbon atoms [55] and the configuration of the double bond (cis or trans) $[53,56]$ affect the kinematic viscosity.

\subsubsection{Surface Tension}

Unlike the density and kinematic viscosity, the surface tension of the bio-oils was measured only in 2020 (Table 5), i.e., bio-oils received in 2015 were measured in 2020, and those received in 2018 were also measured in 2020. The values varied between 32.9 and $33.3 \mathrm{mN} / \mathrm{m}$ at $24{ }^{\circ} \mathrm{C}$, with each measurement accuracies of $\pm 0.03 \mathrm{mN} / \mathrm{m}$. The older bio-oils' surface tension values (received in 2015) were consistently lower than those of the more recent bio-oils (received in 2018). Even if the differences between each measured value were not significant $(\sim 0.5 \%)$, they imply that the storage period has had a minor effect on the bio-oils' overall surface tension.

The narrow range of the surface tension values obtained for the bio-oil samples is consistent with the results observed by Goodrum at al. [37]. They reported that four different triglyceride samples had very close surface tension values. Sahasrabudhe et al. [54] reported similar surface tension values for different samples of vegetable oils. Surface tensions determined by Tyowua et al. [38], using the du Noüy tensiometer method at $25^{\circ} \mathrm{C}$, for sunflower, olive, and rapeseed oils were $32.2,33.1$, and $33.8 \mathrm{mN} / \mathrm{m}$, respectively. 
Given that there was a $1{ }^{\circ} \mathrm{C}$ temperature difference, the surface tension values reported by Tyowua et al. [38] agree with the FOs and UCOs surface tensions determined in our work.

The surface tension of COref was $30.6 \pm 0.007 \mathrm{mN} / \mathrm{m}$ at $24{ }^{\circ} \mathrm{C}$, which is out of the bio-oils range. As described in the Materials section, the composition of COref is mostly aliphatic hydrocarbons, including the largest single compounds in the range C14-C26. According to the data available in [57], the surface tension of hexacosane $\left(\mathrm{C}_{26} \mathrm{H}_{54}\right)$ was reported to be $28.6 \mathrm{mN} / \mathrm{m}$ at $51.8^{\circ} \mathrm{C}$. Considering the general trend of decrease in surface tension with increasing temperature, the measured surface tension of COref is comparable to that of hexacosane $\left(\mathrm{C}_{26} \mathrm{H}_{54}\right)$.

\subsection{Observations}

The physicochemical properties of the bio-oils stored for two and five years showed slow decreasing or increasing trend. Several studies $[21,23,45,58,59]$ suggested that exposure of bio-oils to air, light, traces of metal, elevated temperatures, and moisture can accelerate the deterioration of the properties of bio-oils and/or biodiesels. The observed slow aging of the bio-oils in this work was assumed to depend on the storage conditions: closed plastic bottles, and cold and dark environment. Furthermore, the small physicochemical property changes observed in the cold storage conditions can be considered as an indication of larger changes at elevated temperatures.

\section{Conclusions}

The effect of a prolonged storage time on the physical, chemical, and thermal properties of fish-oils (FOs) and used cooking oils (UCOs) was investigated. Different analytical techniques were applied to examine the effect of storage on their fuel qualities. Based on the results obtained from the different techniques, the following conclusions were drawn.

After five years storage period, greater changes about $4.3 \%$ were measured in the composition of the polymerized triglycerides in FOs than in UCOs. The changes in fatty acids and monoglycerides were smaller in FOs than in UCOs. In general, the total FFAs of the UCOs slightly decreased by $\sim 7.7 \%$ during storage. The decrease in the total FFAs for the UCOs was related to the increased concentration of polymerized triglycerides. The acid number and water content of the bio-oils increased slightly during storage. The acid numbers of the bio-oils were well below the fuel quality limit set, e.g., for fuels in marine engines.

The density of the bio-oil samples did not show any marked changes after the storage periods. The kinematic viscosity increased slightly $\sim 7.9 \%$ with the storage time. The increases in the polymerized triglycerides during storage may have contributed to the viscosity increase. The surface tension values of the bio-oils implied a minor decreasing trend $\sim 0.5 \%$ with prolonged storage time. The average heating value did not significantly change with the storage time. This observation was supported by the unchanged ratio between $\mathrm{C}$ and $\mathrm{H}$ in oils.

The results confirm that storing bio-oils in dark, cold, and air tight plastic containers can retain their fuel quality specifications through a slowed aging process. However, commercial bio-oils with acceptable fuel qualities for usage are usually stored in tanks where the temperature is not as low as in our experiments; in such cases, the aging process may proceed faster.

Supplementary Materials: The following is available online at https:/ / www.mdpi.com/1996-1073/ 14/1/101/s1: Table S1. Composition of bio-oils measured with a gas chromatography (mg/g oil).

Author Contributions: Conceptualization, N.B., L.H., and F.T.; methodology, N.B., J.H., and M.J.D.; formal analysis, N.B., J.H., F.T., L.H., and M.J.D; investigation, N.B., F.T., L.H., J.H., and M.J.D.; writing-original draft, N.B. and F.T.; writing-review and editing, L.H., F.T., J.H., and M.J.D.; supervision, L.H. and F.T.; project administration, L.H.; funding acquisition, N.B., L.H., and F.T. All authors have read and agreed to the published version of the manuscript. 
Funding: This research was funded by the Swedish Cultural Foundation in Finland, and the Academy of Finland project "Thermodynamic investigation of complex inorganic material systems for improved renewable energy and metals production processes" (decision no. 311537). The APC was funded by Åbo Akademi University. VG EcoFuel Oy and Neste Oyj are gratefully acknowledged for providing the oil samples.

Informed Consent Statement: Not applicable.

Data Availability Statement: Data is contained within the article and its supplementary material.

Conflicts of Interest: The authors declare no conflict of interest.

\section{References}

1. Kulkarni, M.G.; Dalai, A.K. Waste cooking oil-An economical source for biodiesel: A review. Ind. Eng. Chem. Res. 2006, 45, 2901-2913. [CrossRef]

2. Capuano, D.; Costa, M.; Di Fraia, S.; Massarotti, N.; Vanoli, L. Direct use of waste vegetable oil in internal combustion engines. Renew. Sustain. Energy Rev. 2017, 69, 759-770. [CrossRef]

3. Mannekote, J.K.; Kailas, S.V. The effect of oxidation on the tribological performance of few vegetable oils. J. Mater. Res. Technol. 2012, 1, 91-95. [CrossRef]

4. Chhetri, A.B.; Watts, K.C.; Islam, M.R. Waste cooking oil as an alternative feedstock for biodiesel production. Energies 2008, 1, 3-18. [CrossRef]

5. Saeed, R.H.S.; Kassem, Y.; Çamur, H. Effect of biodiesel mixture derived from waste frying-corn, frying-canola-corn and canola-corn cooking oils with various ages on physiochemical properties. Energies 2019, 12, 3729. [CrossRef]

6. Behçet, R. Performance and emission study of waste anchovy fish biodiesel in a diesel engine. Fuel Process. Technol. 2011, 92, 1187-1194. [CrossRef]

7. Hemmer, M.; Badent, R.; Ströck, G. Einsatzfähigkeit von Rapsöl als Isoliermedium in Mittelspannungstransformatoren. In Nachwachsende Rohstoffe für die Chemie 8, Tübingen, Germany, 26-27 March 2003; Landwirtschaftsverlag: Münster, Germany, 2003; pp. 591-599.

8. Tye, C.T. Recent advances in waste cooking oil management and applications for sustainable environment. In Handbook of Research on Resource Management for Pollution and Waste Treatment; Affam, A.C., Ezechi, E.H., Eds.; IGI Global: Hershey, PA, USA, 2020; pp. 47-63.

9. Moirangthem, K. Alternative Fuel for Marine and Inland Waterways: An Exploratory Study; European Commission JRC: Luxembourg, 2016; pp. 1-44.

10. European Commission (EC). Reducing Emissions from the Shipping Sector. Available online: https://ec.europa.eu/clima/ policies/transport/shipping_en (accessed on 7 December 2020).

11. Santos, J.C.O.; Santos, I.M.G.; Souza, A.G. Effect of heating and cooling on rheological parameters of edible vegetable oils. J. Food Eng. 2005, 67, 401-405. [CrossRef]

12. Di Pietro, M.E.; Mannu, A.; Mele, A. NMR determination of free acids in vegetable oils. Processes 2020, 8, 410. [CrossRef]

13. Talbot, G. The stability and shelf life of fats and oils. In The Stability and Shelf Life of Food, 2nd ed.; Subramaniam, P., Ed.; Elsevier: Amsterdam, The Netherlands, 2016; pp. 461-503.

14. Marmesat, S.; Rodrigues, E.; Velasco, J.; Dobarganes, C. Quality of used frying fats and oils: Comparison of rapid tests based on chemical and physical oil properties. Int. J. Food Sci. Technol. 2007, 42, 601-608. [CrossRef]

15. Totani, N.; Yawata, M.; Mori, T.; Hammond, E.G. Oxygen content and oxidation in frying oil. J. Oleo Sci. 2013, 62, 989-995. [CrossRef]

16. Gnanasekaran, D. Green fluids from vegetable oil: Power plant. In Vegetable Oil based Bio-lubricants and Transformer Fluids: Applications in Power Plants; Gnanasekaran, D., Chavidi, V.P., Eds.; Springer Nature: Singapore, 2018; pp. 3-26.

17. Gutiérrez González-Quijano, R.; Dobarganes, M.C. Analytical procedures for the evaluation of used frying fats. In Frying of Food: Principles, Changes, New Aproaches; Varela, G., Bender, A.E., Morton, I.D., Eds.; VCH: Weinheim, Germany, 1988 ; pp. 141-154.

18. Enweremadu, C.C.; Mbarawa, M.M. Technical aspects of production and analysis of biodiesel from used cooking oil-A review. Renew. Sustain. Energy Rev. 2009, 13, 2205-2224. [CrossRef]

19. Gertz, C.; Klostermann, S.; Kochhar, S.P. Testing and comparing oxidative stability of vegetable oils and fats at frying temperature. Eur. J. Lipid Sci. Technol. 2000, 102, 543-551. [CrossRef]

20. Tenbohlen, S.; Koch, M. Aging performance and moisture solubility of vegetable oils for power transformers. IEEE Trans. Power Deliv. 2010, 25, 825-830. [CrossRef]

21. Sazzad, B.S.; Fazal, M.A.; Haseeb, A.S.M.A.; Masjuki, H.H. Retardation of oxidation and material degradation in biodiesel: A review. Rsc Adv. 2016, 6, 60244-60263. [CrossRef]

22. Demirbas, A.; Karslioglu, S. Biodiesel production facilities from vegetable oils and animal fats. Energy Sourses Part A 2007, 29, 133-141. [CrossRef]

23. Bouaid, A.; Martinez, M.; Aracil, J. Long storage stability of biodiesel from vegetable and used frying oils. Fuel 2007, 86, 2596-2602. [CrossRef] 
24. Xu, Y.; Qian, S.; Liu, Q.; Wang, Z.D. Oxidation stability assessment of a vegetable transformer oil under thermal aging. IEEE Trans. Dielectr. Electr. Insul. 2014, 21, 683-692. [CrossRef]

25. Fox, N.J.; Stachowiak, G.W. Vegetable oil-based lubricants-A review of oxidation. Tribol. Int. 2007, 40, 1035-1046. [CrossRef]

26. Sidibé, S.S.; Blin, J.; Vaitilingom, G.; Azoumah, Y. Use of crude filtered vegetable oil as a fuel in diesel engines state of the art: Literature review. Renew. Sustain. Energy Rev. 2010, 14, 2748-2759. [CrossRef]

27. Bruun, N.; Khazraie Shoulaifar, T.; Hemming, J.; Willför, S.; Hupa, L. Characterization of waste bio-oil as an alternate source of renewable fuel for marine engines. Biofuels 2019. [CrossRef]

28. Ushakov, S.; Valland, H.; Æsøy, V. Combustion and emissions characteristics of fish oil fuel in a heavy-duty diesel engine. Energy Convers. Manag. 2013, 65, 228-238. [CrossRef]

29. Yin, H.; Solval, K.M.; Huang, J.; Bechtel, P.J.; Sathivel, S. Effects of oil extraction methods on physical and chemical properties of red salmon oils (Oncorhynchus nerka). J. Am. Oil Chem. Soc. 2011, 88, 1641-1648. [CrossRef]

30. Blin, J.; Brunschwig, C.; Chapuis, A.; Changotade, O.; Sidibe, S.S.; Noumi, E.S.; Girard, P. Characteristics of vegetable oils for use as fuel in stationary diesel engines-Towards specifications for a standard in West Africa. Renew. Sustain. Energy Rev. 2013, 22, 580-597. [CrossRef]

31. Jayasinghe, P.; Hawboldt, K. A review of bio-oils from waste biomass: Focus on fish processing waste. Renew. Sustain. Energy Rev. 2012, 16, 798-821. [CrossRef]

32. Adeoti, I.A.; Hawboldt, K. Comparison of biofuel quality of waste derived oils as a function of oil extraction methods. Fuel 2015, 158, 183-190. [CrossRef]

33. Lee, B.B.; Ravindra, P.; Chan, E.S. New drop weight analysis for surface tension determination of liquids. Colloids Surf. A Physicochem. Eng. Aspects 2009, 332, 112-120. [CrossRef]

34. Gianino, C. Measurement of surface tension by the dripping from a needle. Phys. Educ. 2006, 41, 440-444. [CrossRef]

35. Morón-Villarreyes, J.A.; Soldi, C.; DeAmorim, A.M.; Pizzolatti, M.G.; DeMendonça, A.P., Jr.; D'Oca, M.G.M. Diesel/biodiesel proportion for by-compression ignition engines. Fuel 2007, 86, 1977-1982. [CrossRef]

36. Graboski, M.S.; McCormick, R.L. Combustion of fat and vegetable oil derived fuels in diesel engines. Prog. Energy Combust. Sci. 1998, 24, 125-164. [CrossRef]

37. Goodrum, J.W.; Eitcman, M.A. Physical properties of low molecular weight triglycerides for the development of bio-diesel fuel models. Bioresour. Technol. 1996, 56, 55-60. [CrossRef]

38. Tyowua, A.T.; Targeman, M.; Binks, B.P. Comparison of vegetable oil-silicone oil interfacial tension data from the du Noüy ring and the spinning drop methods. Niger. Ann. Pure Appl. Sci. Maiden Ed. 2018, 209-213. [CrossRef]

39. Bruun, N.; Demesa, A.G.; Tesfaye, F.; Hemming, J.; Hupa, L. Factors affecting the corrosive behavior of used cooking oils and a non-edible fish oil that are in contact with ferrous metals. Energies 2019, 12, 4812. [CrossRef]

40. Dirbeba, M.J.; Aho, A.; DeMartini, N.; Brink, A.; Mattsson, I.; Hupa, L.; Hupa, M. Fast pyrolysis of dried sugar cane vinasse at 400 and $500^{\circ} \mathrm{C}$ : Product distribution and yield. Energy Fuels 2019, 33, 1236-1247. [CrossRef]

41. Pölczmann, G.; Tóth, O.; Beck, Á.; Hancsók, J. Investigation of storage stability of diesel fuels containing biodiesel produced from waste cooking oil. J. Clean. Prod. 2016, 111, 85-92.

42. Meng, J.; Moore, A.; Tilotta, D.C.; Kelley, S.S.; Adhikair, S.; Park, S. Thermal and storage stability of bio-oil from pyrolysis of torrefied wood. Energy Fuels 2015, 29, 5117-5126. [CrossRef]

43. Ollus, R.; Juoperi, K. Alternative fuels experiences for medium-speed diesel engines. In Proceedings of the 25th CIMAC Congress on Combustion Engine Technology, Vienna, Austria, 21-27 May 2007; International Council on Combustion Engines: Frankfurt, Germany, 2007.

44. Karmakar, A.; Karmakar, S.; Mukherjee, S. Properties of various plants and animals feedstocks for biodiesel production. Bioresour. Technol. 2010, 101, 7201-7210. [CrossRef]

45. Gregg, F. SVO: Powering Your Vehicle with Straight Vegetable Oil; New Society Publishers: Gabriola Island, BC, Canada, 2008; pp. 29-79.

46. Yahyaee, R.; Ghobadian, B.; Najafi, G. Waste fish oil biodiesel as a source of renewable fuel in Iran. Renew. Sustain. Energy Rev. 2013, 7, 312-319. [CrossRef]

47. Wisniewski, A.; Wiggers, V.R.; Simionatto, E.L.; Meier, H.F.; Barros, A.A.C.; Madureira, L.A.S. Biofuels from waste fish oil pyrolysis: Chemical composition. Fuel 2010, 89, 563-568. [CrossRef]

48. Abidin, S.Z.; Patel, D.; Saha, B. Quantitative analysis of fatty acids composition in the used cooking oil (UCO) by gas chromatography-mass spectrometry (GC-MS). Can. J. Chem. Eng. 2013, 91, 1896-1903. [CrossRef]

49. Czernik, S.; Bridgwater, A.V. Overview of applications of biomass fast pyrolysis oil. Energy Fuels 2004, 18, 590-598. [CrossRef]

50. Hoekman, S.K.; Broch, A.; Robbins, C.; Ceniceros, E.; Natarajan, M. Review of biodiesel composition, properties, and specifications. Renew. Sustain. Energy Rev. 2012, 16, 143-169. [CrossRef]

51. Wahyudi, W.; Nadjib, M.; Bari, M.F.; Permana, F.W. Increasing of quality biodiesel of Jatropha seed oil with biodiesel mixture of waste cooking oil. J. Biotech Res. 2019, 10, 183-189.

52. Jiménez Espadafor, F.; Torres García, M.; Becerra Villanueva, J.; Moreno Gutiérrez, J. The viability of pure vegetable oil as an alternative fuel for large ships. Transp. Res. Part D. 2009, 14, 461-469. [CrossRef]

53. Liu, Z.W.; Li, F.S.; Wang, W.; Wang, B. Impact of different levels of biodiesel oxidation on its emission characteristics. J. Energy Inst. 2019, 92, 861-870. [CrossRef] 
54. Sahasrabudhe, S.N.; Rodriguez-Martinez, V.; O'Meara, M.; Farkas, B.F. Density, viscosity and surface tension of five vegetable oils at elevated temperatures: Measurement and modeling. Int. J. Food Prop. 2017, 20, 51965-51981. [CrossRef]

55. Prankl, H.; Wörgetter, M.; Rathbauer, J. Technical performance of vegetable oil methyl esters with a high iodine number. In Proceedings of the 4th Biomass Conference of the Americas, Oakland, CA, USA, 29 August-2 September 1999.

56. Knothe, G.; Steidley, K.R. Kinematic viscosity of biodiesel fuel components and related compounds. Influence of compound structure and comparison to petrodiesel fuel components. Fuel 2005, 84, 1059-1065. [CrossRef]

57. Yaws, C.L.; Richmond, P.C. Chapter 21 - Surface tension-Organic compounds. In Thermophysical Properties of Chemicals and Hydrocarbons; Yaws, C.L., Ed.; William Andrew Publishing: Norwich, NY, USA, 2009; pp. 686-781. [CrossRef]

58. Bajpai, D.; Tyagi, V.K. Biodiesel: Source, production, composition, properties and its benefits. J. Oleo Sci. 2006, 55, 487-502 [CrossRef]

59. Das, L.M.; Bora, D.K.; Pradhan, S.; Naik, M.K.; Naik, S.N. Long-term storage stability of biodiesel produced from Karanja oil. Fuel 2009, 88, 2315-2318. [CrossRef] 